\title{
The Consequences of Chronic Stereotype Threat: Domain Disidentification and Abandonment
}

\author{
Anna Woodcock, \\ Department of Psychological Sciences, Purdue University \\ Paul R. Hernandez, \\ School of Education, Colorado State University \\ Mica Estrada, and \\ Department of Psychology, California State University, San Marcos \\ P. Wesley Schultz \\ Department of Psychology, California State University, San Marcos
}

\begin{abstract}
Stereotype threat impairs performance across many domains. Despite a wealth of research, the long-term consequences of chronic stereotype threat have received little empirical attention. Beyond the immediate impact on performance, the experience of chronic stereotype threat is hypothesized to lead to domain disidentification and eventual domain abandonment. Stereotype threat is 1 explanation why African Americans and Hispanic/Latino(a)s "leak" from each juncture of the academic scientific pipeline in disproportionately greater numbers than their White and Asian counterparts. Using structural equation modeling, we tested the stereotype threatdisidentification hypothesis across 3 academic years with a national longitudinal panel of undergraduate minority science students. Experience of stereotype threat was associated with scientific disidentification, which in turn predicted a significant decline in the intention to pursue a scientific career. Race/ethnicity moderated this effect, whereby the effect was evident for Hispanic/Latino(a) students but not for all African American students. We discuss findings in terms of understanding chronic stereotype threat.
\end{abstract}

\section{Keywords}

stereotype threat; academic identification; structural equation modeling; longitudinal research; scale validation

Despite the strong sense we have of ourselves as autonomous individuals, evidence consistently shows that contingencies tied to our social identities do make a difference in shaping our lives, from the way we perform in certain situations to the careers and friends we choose.

\section{—Claude M. Steele, Whistling Vivaldi}

Stereotype threat provides a rich theoretical context for understanding the impact of pervasive social stereotypes on members of stigmatized groups. Stereotype threat research has focused largely on the moderators and processes underlying the immediate impact of 
stereotypes on performance (C. M. Steele, Spencer, \& Aronson, 2002). Beyond the immediate impairment of performance, C. M. Steele (1997) posited that a long-term psychological consequence of stereotype threat is domain disidentification, whereby members of negatively stereotyped groups progressively place less importance on their performance in the stereotyped domain. For instance, as a consequence of numerous stereotype-threatening experiences, women may lose interest in doing well in math and science, or Black and Hispanic students may cease to care about their grades. In academic spheres, there are substantial consequences of disidentification. Stigmatized individuals are disadvantaged when they disidentify and eventually leave the academic pipeline, and the professions that draw from those pipelines are left with a less diverse talent pool.

C. M. Steele et al. (2002) distinguished between domain disengagement and disidentification:

First, disengagement and disidentification can be thought of as end points on a continuum of self-protective, ego withdrawal from a domain and its standards. At the disengagement end, their withdrawal is a more immediate reaction to the experience of stereotype threat....at the other end of the continuum, a complete disidentification is realized in which the person has no ego dependence on the domain and may resist any encouragement to develop one. (p. 412)

Throughout the present article, we use the term domain disengagement to denote an immediate response to stereotype threat. Domain disidentification denotes the more permanent separation of the self and the domain in question in response to chronic stereotype threat across time.

There is empirical support for domain disengagement as an immediate consequence of stereotype threat. For example, women exposed to gender-stereotypic television commercials later avoid math items in favor of verbal items on a standardized test and indicate fewer aspirations toward math-related vocations than those who did not view the commercials (Davies, Spencer, Quinn, \& Gerhardstein, 2002). Stereotype threat significantly reduces women's aspirations toward leadership roles (Davies, Spencer, \& Steele, 2005). The mere prospect of being in the numerical minority decreases women's sense of belonging and their desire to attend professional events in male-dominated domains (Murphy, Steele, \& Gross, 2007). Finally, African Americans experiencing stereotype threat disengage from academics in response to negative performance feedback (Nussbaum \& Steele, 2007).

There is some longitudinal evidence that the development of domain identification is arrested in response to stereotype threat. Women in a college calculus course with greater initial implicit male $=$ math stereotype activation had lower final exam scores and lower math-intensive career goals at the end of the semester than women with lower negative implicit stereotype activation (Kiefer \& Sekaquaptewa, 2007). This indicates that the salience of gender stereotypes has negative effects on future performance and domain identification. However, the impact of chronic stereotype threat on domain identification and persistence over a longer span of time remains unclear. The aim of the present research was to explore this process.

Stereotype threat can be induced by a number of means, such as diagnosticity of task performance (Steele \& Aronson, 1995), blatant stereotypic statements (Spencer, Steele, \& Quinn, 1999; Stone, Lynch, Sjomeling, \& Darley, 1999), and contextual cues such as stereotypic cartoons (Oswald \& Harvey, 2000). Evidence suggests that simply being in the numerical minority in a stereotyped domain is stereotype threatening (Inzlicht \& Ben-Zeev, 2000). Being in the numerical minority and in a stereotype-threatening situation created by 
other situational cues has an additive effect, whereby performance is reduced to a point lower than in threat or minority status conditions alone (Sekaquaptewa \& Thompson, 2003). This last finding indicates that the diversity of the environment can moderate the experience of stereotype threat. A diverse environment may exacerbate its effects for minority group members, but a more homogenous environment in which minority group members are the numerical majority may offer protection. This is particularly relevant to the present research.

\section{Domain Disidentification}

Domain disidentification occurs when a formerly valued social identity is significantly reduced or abandoned. Social identities are not static, but are believed to be in constant flux. Thus, the strength of social identities of both stigmatized and nonstigmatized individuals are continually negotiated and renegotiated as part of normal psychological functioning (Deaux $\&$ Ethier, 1998). The persistent experience of stereotype threat is hypothesized to have an erosive effect on domain identity (e.g., math or academic identity). Ironically, the more one's identity and self-worth are contingent upon doing well in a particular (negatively stereotyped) domain, the more threatening negative stereotypes and the fear of conforming to them becomes. Disidentifying and putting some psychological distance between the stereotyped domain and the self is one way to mitigate this threat (Major \& Schmader, 1998). Steele et al. (2002) theorized that this is a chronic adaptation to stereotype threat.

Disidentification from a once valued domain is a process that plays out over time, with disengagement being the first step. When attempting to disengage from the domain, stigmatized individuals can strategically protect their self-concept by either devaluing the domain itself (e.g., "education isn't important") or by discounting the validity of performance feedback in the domain as an indicator of their abilities (e.g., "I feel that standardized achievement tests are definitely biased against me"; Major \& Schmader, 1998; Schmader, Major, \& Gramzow, 2001).

Race/ethnicity may be a moderator of the stereotype threat and domain disidentification process. Both African Americans and Latino(a)s discount and devalue academics (Schmader et al., 2001), but their antecedents differ slightly. Weak academic performance predicts devaluing, and perceptions of ethnicity-based injustice predicts discounting for Latino(a)s and perceptions of ethnicity-based injustice predicts discounting for African Americans, but to a lesser extent than for Latino(a)s. The disengagement strategies used by African Americans and Latino(a)s in response to their academic environments are not identical and may influence how they respond to chronic stereotype threat.

\section{Domain Identification and Stereotype Threat}

Stereotype threat has the greatest impact on individuals with high ability who are highly identified with the domain in question (Aronson et al., 1999; Stone, 2002). Thus, domain identification has an ironic relationship with stereotype threat that puts members of a group whose performance is negatively stereotyped in a psychological bind. On the one hand, highly domain-identified individuals are more susceptible to the negative performance effects of stereotype threat than those who are less identified (Aronson et al., 1999; Stone, 2002). On the other hand, the experience of stereotype threat is theorized to lead to domain disidentification - at the time that domain identification is crucial for academic performance and persistence (C. M. Steele, 1997).

There is a paucity of research that looks specifically at the process of domain disidentification as a long-term consequence of persistent stereotype threat. Preliminary evidence shows a pattern of diminishing correlations between Black eighth and 12th graders' self-esteem and grades (Osborne, 1997). Interestingly, this pattern emerges only for 
African American boys, and not for Latinos or Latinas, indicating that academic disidentification in the face of chronic stereotype threat may operate differently for different stigmatized groups. This is consistent with theorizing that stereotype threat is triggered and experienced differently across different stigmatized groups (Shapiro \& Neuberg, 2007).

Domain disidentification is a dynamic process. There appears to be a recursive effect of stereotype threat and domain disengagement whereby chronic exposure to stereotypethreatening situations repeatedly impairs performance, triggering repeated instances of defensive disengagement to protect the self. This recursive pattern spirals downward across time, whereby repeated instances of defensive separation of performance in the domain at hand from the self causes stigmatized individuals to disidentify. The process ends with domain abandonment when the contingency of self-worth is no longer linked to performance in the domain. The association between the experience of chronic stereotype threat and domain disidentification may be moderated by the way stigmatized individuals disengage in the face of negative experiences. Repeatedly devaluing the domain itself may more readily invoke domain disidentification than discounting the validity of negative feedback. Prior to testing a complex model of behavior over time, evidence for the broader stereotypedisidentification hypothesis must be obtained. The aim of this research was to establish the overall pattern of stereotype threat leading to domain disidentification and abandonment over time.

Longitudinal studies are needed to capture the disidentification process, as the association between domain identity and stereotype threat is dynamic. Theoretically, those with high domain identification are the most likely to experience stereotype threat initially, compared with their less identified counterparts (Aronson et al., 1999; Keller, 2007). Over time, however, the cumulative effect of chronic stereotype threat should reverse this association whereby stereotype threat and academic identity become negatively related. Complex processes are challenging to measure. Depending on the specifics of the sample, crosssectional studies may capture one, or both, of these effects. When research captures both of these associations, the true relation between identification and stereotype threat can be obscured.

Conflicting research findings may provide evidence of the dynamic nature of domain identification in the context of chronic stereotype threat. For instance, in a field study of African American and White undergraduates, identification with academic achievement was unrelated to perceptions of stereotype threat (Aronson, Fried, \& Good, 2002). However, Cokley (2002) found a significant positive association between academic self-concept and performance for African American male first- and second-year undergraduates $(r=.52)$, but no association for African American male juniors and seniors $(r=.17)$. No shift in the relation between academic self-concept and performance across grade level was detected for female African Americans. Analyses of data from large, extant data sets also offer clues. Massey and Fischer (2005) found that the internalization of negative stereotypes about the intellectual inferiority of their groups (used as an indicator of stereotype threat) was a significant negative predictor of academic effort (an indicator of identification) in Black and Latino first-year students. Morgan and Mehta (2004) found that Black high school students discounted performance evaluations but did not show evidence of decreased identification with school. Findings from analyses of extant data sets are limited by the use of existing variables as proxies for the constructs in question. No specific program of research has directly tested the stereotype threat-disidentification hypothesis. This was the aim of the present research. 


\section{African Americans and Hispanics in the Sciences}

One source of evidence that domain disidentification is occurring for negatively stereotyped populations is the considerable academic participation gap in the United States between underrep-resented minorities and their White and Asian counterparts. In particular, African Americans and Hispanic/Latino(a)s are under-represented at all levels of higher education in the United States, especially in the sciences. The detrimental impact of stereotype threat on performance has been implicated in this ongoing disparity (Cokley, 2002; Singham, 1998). If true, then we would expect to find evidence of disidentification and attrition as consequences of persistent stereotype threat for African Americans and Hispanic/Latino(a)s in the sciences. Both groups are negatively stereotyped in these academic domains and are a clear numerical minority in the academic science pipeline.

The central aim of this research was to test the stereotype threat-disidentification hypothesis in minority science students. We examined the mediating role of domain disidentification on the long-term relation between chronic stereotype threat and intention to persist in the sciences. In doing so, we examined (a) how undergraduate minority science students experience chronic stereotype threat during their journey toward a scientific career, (b) the relation between the experience of chronic stereotype threat and disidentification with the sciences over time, (c) the impact of scientific disidentification on persistence in the scientific pipeline in the pursuit of a scientific career, and (d) the extent to which these processes occur for both African Americans and Hispanic/Latino(a)s.

\section{Method}

Participants

Findings reported here are drawn from the first three academic years of data from The Science Study, a panel study of 1,420 predominantly African American and Hispanic/ Latino(a) science students (Schultz, 2012). Panel members are all high-achieving and highly identified science students whose goal at the time of entering the panel was a doctoral-level scientific research career. The panel was recruited during 2005 from 50 colleges and universities across the United States with the aim of tracking the educational and career trajectories of minority students in the scientific pipeline. Panel members were recruited on the basis of being a member of a race/ethnicity group underrepresented in the sciences, having a declared major in the sciences, self-report a high grade point average (GPA) $(M=$ $3.32, S D=0.43)$, and a goal of pursuing a doctoral-level scientific research career $(M=$ $8.39, S D=1.90$, on a 0 [definitely will not] to 10 [definitely will] scale). Panel members were recruited by contacting professors teaching large undergraduate science classes and the directors of minority intervention programs in science to promote the study to their students. ${ }^{1}$ Science students were paid $\$ 5$ (online gift code) to complete the short screening survey to join the study panel.

\section{Procedure}

Data were collected via semiannual online surveys administered during the spring and fall. Each survey wave includes questions pertaining to college enrollment, degree attainment, academic performance, and career interests and aspirations. In addition, measures of psychological constructs such as ethnic, academic, and scientific identity; self-esteem; subjective happiness; academic motivation; and perceptions of stereotype threat and the

\footnotetext{
${ }^{1}$ Intervention programs for minorities in the sciences exist on many campuses, and program directors typically recruit the most promising minority science students into their programs. Students were recruited from campuses with minority programs and those with no such programs. Fifty-five percent of students at the programs we approached joined the Science Study research panel, and there were no significant differences in gender, race/ethnicity, or age between those who joined and those who did not.
} 
climate of the scientific community are assessed annually. Participants receive \$25 compensation per survey.

To maximize participant commitment to the research panel and survey response rates, we maintained regular contact with participants during and beyond their undergraduate enrollment (Tailored Panel Management: Woodcock et al., 2009). Over the first four waves of data collection, survey response consistently exceeded $75 \%$ (range $=75 \%-85 \%$ ). This high response rate was maintained when students left their baccalaureate institution and moved into postgraduate education or the workforce.

\section{Measures}

Stereotype threat-Stereotype threat was measured each fall with a modified version of the eight-item Stereotype Vulnerability Scale (SVS; Spencer, 1994). The SVS was developed and used by Spencer in work examining the impact of stereotype threat on the performance of women on math tests. Spencer's (1994, Study 5) work provides strong evidence of the construct validity of the scale. In an experimental study of stereotype threat, women performing a difficult math test under conditions of stereotype threat versus no threat reported significantly higher levels of stereotype vulnerability measured by the eightitem scale. The SVS has been used in published stereotype threat studies involving African Americans performing in academic domains (Aronson et al., 2002) and women performing in male-dominated academic domains (J. R. Steele, James, \& Barnett, 2002), but has yet to be psycho-metrically evaluated. The original SVS items were modified to reflect perceived judgments of others on the basis of ethnicity. Relating the SVS questions to their "experiences at college," participants used the stem phrase "How often do you feel that because of your ethnicity....", and responded to each SVS item (e.g., "Some people believe that you have less ability") on a 5-point scale, ranging from 1 (never) to 5 (almost always). Scale items were presented in random order (see the Appendix for wording).

Scale validation-Longitudinal mediation analyses rely on measures of latent constructs that are robust across time (Cole \& Maxwell, 2003), so the present measures were psychometrically validated in a large sample of ethnically/racially under-represented college students using confirmatory factor analysis (CFA). Criteria and cutoffs for assessing fit in the CFA models were selected a priori. Following Hu and Bentler (1999), in addition to the model chi-square, a root-mean-square-error of approximation (RMSEA) value at or below . 05 (or a $90 \%$ CI that includes .05 but does not include .10) and the comparative fit index (CFI) value at or above .95 were chosen. Furthermore, when nested models are compared, the $\Delta x^{2}$ test was used to evaluate misfit (Kline, 2005). This analysis used the Year 1 (fall) data from the 313 African American and 250 Hispanic/Latino(a) undergraduate science students who had complete data for the stereotype threat items.

To assess the fit of the original eight-item SVS scale, we allowed all items to load onto the stereotype threat factor (see Figure 1A). The original eight-item model did not exhibit acceptable fit to the data, $\mathrm{X}^{2}(20)=423.53, p<.001 ; \mathrm{CFI}=.85$; RMSEA $=.19,90 \%$ CI [ $17, .21]$. Numerous items exhibited redundant content, leading to a complex pattern of correlated residuals. Therefore, four redundant items were removed in order to derive a measurement model that preserved simple structure (see Figure 1B). The resulting four-item measurement model exhibited excellent fit to the data, $\mathrm{X}^{2}(2)=2.76, p=.251$, and indicates that this subset of items from the original eight-item scale form a reliable self-report measure of stereotype threat $(\alpha=.85)$. Items included in the shortened Stereotype Vulnerability Scale (SVS-4) are shown in the Appendix. 
Scientific identity-Scientific disidentification was assessed using a measure of scientific identity. Disidentification from the sciences was quantified as the inverse of scientific identification. For example, a negative association between stereotype threat and scientific identity would indicate disidentification. Specifically, a five-item subset of Chemers' (2006) Scientific Identity Scale (see Estrada, Woodcock, Hernandez, \& Schultz, 2011, for psychometric evaluation) was used and measured each fall. Participants indicated the extent that each of the following statements was true of them on a scale of 1 (strongly disagree) to 5 (strongly agree): "I have a strong sense of belonging to the community of scientists"; "I derive great personal satisfaction from working on a team that is doing important research"; "I have come to think of myself as a "scientist"; "I feel like I belong in the field of science"; and "The daily work of a scientist is appealing to me."

Persistence in the sciences-Plans to remain in or abandon the sciences was measured by participants' response to the question "To what extent do you intend to pursue a sciencerelated research career?" on a scale of 0 (definitely will not) to 10 (definitely will). This item was asked in each wave of survey collection. The fall survey data were used for the research reported here.

All measures were completed during Years 1, 2, and 3 of the study (see Table 1 for interitem correlations and measures of internal consistency).

\section{Cross-Ethnic and Longitudinal Measurement Invariance of Stereotype Threat and Scientific Identity Scales}

The measurement invariance of the stereotype threat and scientific identity measures were tested between the present sample of African American and Hispanic/Latino(a) participants, and across the 3 years of the study. Following current standards, a series of multigroup CFAs was run to test the cross-ethnic longitudinal measurement invariance of both scales (Cole \& Maxwell, 2003). Cross-ethnic measurement invariance was tested separately at each measurement occasion (i.e., African American vs. Hispanic/Latino(a) at Year 1, at Year 2, and at Year 3), whereas longitudinal measurement invariance was tested separately within African American and Hispanic/Latino(a) groups across all measurement occasions (e.g., African American group at Years 1, 2, and 3). Participants were the African American and Hispanic/Latino(a) undergraduate science students in the previous analysis. Participants' responses to surveys conducted from Year 1 through Year 3 are included in these analyses (see Table 2 for descriptive statistics and samples sizes).

After a preliminary test of the measurement models separately for the African American and Hispanic/Latino(a) groups, tests of cross-ethnic measurement invariance were run at each time point (i.e., Year 1, Year 2, and Year 3). Analyses indicated psychometric stability across groups. In addition, tests of longitudinal measurement invariance indicated the pattern of factor loadings, the magnitude of factor loadings, and the item-level means (i.e., configural, metric, and scalar invariance) of the SVS-4, and the Science Identity scales were stable over time for the African American and the Hispanic/Latino(a) groups (see Table 3).

\section{Stereotype Threat and Disidentification Across Time}

Here, the hypothesis that chronic stereotype threat leads disidentification with the sciences and eventual abandonment the pursuit of a scientific career was tested. It was hypothesized. that minority science students who experience stereotype threat during the course of their scientific training will have decreased intention to pursue a scientific career. Furthermore, it was hypoth esized that disidentification with the sciences will mediate this process. Specifically, the expectation was that the experience stereotype threat in Year 1 will be negatively associated with. scientific identification in Year 2 (controlling for prior levels 
scientific identification). Subsequently, scientific identification Year 2 will be associated with intention to pursue a scientific career in Year 3 (controlling for prior levels of intention). Prelim inary mediation analyses were conducted using regression, and mediational analyses were then performed within a structural equation modeling (SEM) framework. The conceptual model outlined in Figure 2. SEM was chosen for our final analysis as allows for error-free measurement and does not restrict our longi tudinal analyses to participants who complete every survey, but allows us to use all available data (Kline, 2005).

A subset of the participants from the previous analyses were selected. A cohort of 283 sophomore $(49 \%)$ and junior undergraduates was tracked across 3 academic years. One hundred sixty-six were African American, and 117 were Hispanic/Latino(a). Seventy-two percent were women. The percentage of women reflects the panel as a whole and does not differ from the gender composition of the undergraduate populations from which they were drawn. The mean age was 20. Sixty-three percent were majoring in the biological sciences; $21 \%$ in the natural sciences; and the remainder in engineering, computer sciences, or psychological sciences. Their mean GPA was 3.32. Of the participants, $77 \%$ were native English speakers, and $17 \%$ had transferred from a junior or community college. Eighty-five percent of the African American participants attended predominantly Black institutions, and $56 \%$ of the Hispanic/Latino(a)s attended Hispanic Serving Institutions.

Sophomores and juniors were selected from our larger undergraduate sample as they have had the opportunity for sufficient exposure to the academic scientific community to establish a scientific identity. They have also been affected by the climate (welcoming or threatening), and are at a point in their academic careers where they are faced with making graduate school plans. A graduate degree is crucial for a career in the sciences, and baccalaureate graduation is a particularly leaky juncture in the scientific academic pipeline. We felt that 3 years was sufficient to capture the stereotype-disidentification effect.

\section{Results and Discussion}

\section{The Experience of Stereotype Threat}

There was evidence of the perception of stereotype threat for both African Americans and Hispanic/Latino(a)s during each year (see Table 2). The mean level of both groups approach the midpoint of the scale that ranges from never experiencing threat to almost always experiencing it. This is interesting given that the majority of the sample was drawn from institutions where the participants' ethnic/racial group was in the numerical majority. African Americans report significantly higher levels of stereotype threat $t_{\text {year }}(273)=3.23$, $p=.001, d=.58$; however, interpreting this difference is difficult, as the SVS-4 items exhibited differential item function.

\section{Longitudinal Analyses}

Given the different experience of stereotype threat between African Americans and Hispanic/Latino(a)s and evidence that members of these groups use different disengagement strategies (Schmader et al., 2001), we conducted preliminary mediational analyses with separate regression equations for African Americans and Hispanic/Latino(a)s. Following Preacher and Hayes (2008), we used a bootstrapping approach to derive a point estimate of the indirect effect representing the effect of stereotype threat on intention to pursue a scientific research career through science disidentification. The mediational effect for Hispanic/Latino(a)s was -0.18 ( $S E=0.11,95 \%$ CI $[-0.46,-0.02])$. The confidence interval does not contain zero, so we can conclude there is a significant mediational effect. The mediated effect for African Americans was -0.02 ( $S E=.08,95 \%$ CI $[-0.21,0.12])$. The confidence intervals contain zero, so we cannot conclude that there is a significant mediation 
effect of stereotype threat on intention to pursue a scientific research career though science disidentification. However, it is known that estimates from regression analyses are biased because they do not control for prior standing on the mediator or outcome variables (Cole \& Maxwell, 2003).

Following Cole and Maxwell (2003), we used SEM to test more precisely the longitudinal mediational effects. We constructed a baseline model that correlated latent stereotype threat, latent science identity, and observed the students' intention to pursue a scientific research career at three occasions (Year 1 through Year 3). The baseline SEM indicated adequate fit to the longitudinal data (see Table 3: Longitudinal Mediation Models: M16). Next, we fit our hypothesized process model to the data (see Figure 3). The process model consists of three key components: (a) correlational relations in Year 1; (b) an autoregressive longitudinal model, wherein each construct at Year 2 was regressed on Year 1 (e.g., stereotype threat at Year 2 was regressed on stereotype threat at Year 1), and each construct at Year 3 was regressed on both Year 2 and Year 1 (e.g., stereotype threat at Year 3 was regressed on stereotype threat at Years 2 and 1); and (c) most importantly, tests of the hypothesized effect of stereotype threat on identity and effect of identity on student intentions. Thus, although we had constrained all of the nonhypothesized paths to zero (e.g., path from Science Identity Year 1 to Stereotype Threat Year 2), the process model did not significantly worsen model fit compared with the baseline model (see Table 3: M17). ${ }^{2}$ Given the acceptable model fit, we examined the hypothesized direct effect of stereotype threat on identity and of scientific identity on intention to pursue a scientific career. We were surprised to see that the hypothesized effect of stereotype threat on identity (disidentification hypothesis) was nonsignificant ( $\beta=-.09, b=-0.05, S E=0.04, p=.11$ ). We suspected that this nonsignificant effect was due to collapsing across groups of African Americans and Hispanic/Latino(a)s, as our regression analyses indicated that their responses to stereotype threat were qualitatively different. Therefore, we reran the baseline and process models as multigroup models.

The multigroup baseline model provided adequate fit (see Table. 3: M18), and the multigroup process model did not worsen model - fit (see Table 3: M19). As suspected, we found that the effect of stereotype threat (Year 1) on scientific identity (Year 2) varied by, race/ethnicity, such that the direct effect was negative and statistically significant for Hispanic/Latino(a)s $(\beta=-.25, b=-0.15, S E=0.05, p=.001)$, but was negative and nonsignificant for African Americans $(\beta=-.03, b=-0.02, S E=0.06, p=.73)$. The direct effect of scientific identity (Year 2) on intention to pursue a scientific career (Year 3) was positive and statistically significant for both groups, Latino(a): $\beta=.28, b=1.09, S E=0.47$, $p<05$; African Americans: $\beta=.24, b=1.00, S E=0.46, p<.05$.

Assessment of indirect effects (mediation)—Having found evidence of statistically significant direct effects, we examined the indirect effect of stereotype threat (Year 1) on intention to pursue a scientific career (Year 3), through scientific identity (Year 2), separately for African Americans and Hispanic/Latino(a)s. As predicted, stereotype threat is negatively associated with intention to persist in the sciences through disidentification with the science for Hispanic/Latino(a) students. However, the process was not the same for the African American students. The absence of a significant direct effect from stereotype threat on identity precluded the hypothesized indirect effect.

\footnotetext{
${ }^{2}$ We also examined paths that did not fit with our theoretical model. Thus, we examined the effect of science identity on stereotype threat (e.g., Stereotype Threat Year 2 regressed on Science Identity Year 1) as well as the effect of intention on science identity and stereotype threat (e.g., Stereotype Threat Year 2 regressed on Intention Year 1). Consistent with our hypothesized model, none of the nonhypothesized paths were statistically significantly different from zero. Therefore, we did not include nonhypothesized paths in any of the proceeding models.
} 
This finding was curious but not entirely unexpected as there is evidence that African Americans strategically disengage in the face of threat in a different manner from Hispanic/ Latino(a)s (Major \& Schmader, 1998). Another plausible explanation is that many of the African American science students in our sample were in an environment that may have buffered their scientific identity from the effects of stereotype threat, if not the perceived experience of it. Our African American sample was drawn from predominantly Black and mixed-race institutions. We hypothesize that although there is no evidence to suggest that the ethnic/racial diversity of the institution predicts the experience of stereotype threat of African Americans $(b=-.04), t(158)=0.02, p=.88$, their critical mass at predominantly Black institutions may shield their scientific identity.

Indeed, further probing of the African American sample indicated a moderating effect of context. Regression analyses, $F(4,114)=22.05, p<.001, R^{2}=.44$, revealed a marginally significant interaction between stereotype threat (Year 1) and the racial diversity of the college on scientific identity (Year 2) controlling for science identity (Year 1) $(b=.38)$, $t(114)=1.76, p=.08$. The racial diversity of the institution did not have an influence on the science identity of African Americans who experienced less stereotype threat in Year 1. However, for African Americans perceiving greater levels of stereotype threat in Year 1, those at racially diverse institutions had greater scientific identity (less disidentification) than those at majority Black institutions. This interaction needs to be interpreted with caution given the majority of our sample come from institutions with very little ethnic/racial diversity.

\section{General Discussion}

C. M. Steele (1997) posited that a long-term consequence of the experience of chronic stereotype threat is a process of disidentification from the domain in question. This separation of the relevance of performance in the domain to an individual's sense of selfworth is hypothesized to lead to eventual abandonment of the domain. To date, no longitudinal empirical test of this process has been reported. The central objective of this research was to test the stereotype threat-disidentification hypothesis in a prospective longitudinal study of underrepresented minority students in the scientific academic pipeline. Across 3 academic years, we demonstrated that both African American and Hispanic/ Latino(a) students experience stereotype threat during their journey toward a scientific career, with African Americans reporting significantly higher levels of threat than Hispanic/ Latino(a)s. In a direct test of the stereotype threat-disidentification hypothesis, we found a moderating effect of race/ethnicity whereby the hypothesis held for Hispanic/Latino(a)s. Specifically, scientific disidentification was a negative predictor of intention to persist in the sciences in the pursuit of a scientific research career for all of the minority science students in our sample, but the experience of stereotype threat was not a significant predictor of scientific disidentification for African Americans.

The nature of our sample of African Americans offers two plausible explanations for our findings. On the one hand, African Americans in the sciences may experience and react to threat differently than Hispanic/Latino(s). Hispanic/Latino(a)s tend to devalue the domain in response to the perception of ethnic-based injustice, whereas African Americans tend to discount the validity of performance feedback (Major \& Schmader, 1998). This may moderate the impact of stereotype threat on domain disidentification. Hispanic/Latino(a)s disengagement via devaluaing the domain facilitate disidentification. However, in the case of African Americans, discounting performance feedback may not lead to the need to defensively disidentify with the sciences - another mechanism may be in place. 
On the other hand, these finding suggest that contextual variables such as a critical mass of one's stigmatized ingroup may change the nature of the experience of stereotype threat. When a member of an identity-stigmatized group is in the numerical minority, the experience of stereotype threat may have a negative impact on domain identity and result in protective bifurcation of the self-concept and the stigmatized domain. In contrast, when in the numerical majority, a stereotype-threatened individual may become more likely to maintain a positive domain-specific self-concept given the existence of a positive ingroup identity. Indeed, social identity theory posits that individuals draw self-worth from positive social identities and personal identity (Turner, 1975). In contexts such as majority Black institutions, African American scientists in training have a positive and valued identity as an African American to draw on and buffer their self-concept from the effects of stereotype threat. This may serve to reduce the psychological need to distance themselves from the sciences in order to maintain positive self-worth. Training to be a scientist at a majority Black institution may also have the effect of rendering the oft incompatible identities of being African American and being a scientist more compatible. This idea is echoed in research of women undergraduates in single-sex intervention programs at coeducational colleges. Engagement in science, technology, engineering, and mathematics (STEM) was predicted by perceived social support from people affiliated with the program and perceived compatibility between the identities of being a women and being in a STEM field (Rosenthal, London, Levy, \& Lobel, 2011). Although we acknowledge that the selfselection of students into mixed- or single-race environments raises possible confounds, the positive personal identity and identity compatibility hypotheses are plausible explanations for our findings.

It is impossible to tease apart the influence of ethnicity and critical mass on the process underlying the long-term consequences of stereotype threat for the African Americans in this sample. However, these findings have substantial theoretical and practical implications. The situational effects of stereotype threat on performance and domain disengagement appear to be robust across many stereotyped domains, but the long-term, dynamic relation between chronic stereotype threat and domain identification may be more nuanced than originally hypothesized. Our study was focused on the consequences of chronic stereotype threat on the intended persistence of underrepresented minorities in the scientific pipeline. Arguably, these students have overcome stereotype threat and other psychological barriers already and may represent a particularly resilient population. The stereotype threatdisidentification process may be more pronounced in a sample less far along the academic pipeline.

It is clear that a great deal of additional research will be required to integrate fully a number of psychological processes in the refinement of the theoretical underpinnings of adapting to chronic stereotype threat. It will be important to understand the situational factors that facilitate or buffer individuals experiencing stereotype threat from domain disidentification to gain a clearer understanding of the process of chronic stereotype threat. It is our hope that this initial evidence that members of different stigmatized groups have divergent psychological responses to the experience of chronic stereotype threat will provide a springboard for future research.

This research also has substantial practical implications. Many individuals and institutions involved in efforts to address gender and racial/ethnic disparities are beginning to look to the psychological impact of negative stereotypes (Burgess, Warren, Phelan, Dovidio, \& van Ryn, 2010; Cokley, 2002; Hill, Corbett, \& St. Rose, 2010; Singham, 1998). These practical efforts will require an understanding of both the contextual influence and long-term consequences of stereotype threat. After reviewing the stereotype threat literature, it is conceivable that one would come away with the impression that the stereotype threat- 
disidentification process is robust and ubiquitous. Our evidence of a moderating effect of context on the stereotype threat-disidentification process suggests further empirical tests of this assumption are needed.

A second important and unique contribution of this research is the validation of a self-report measure of stereotype threat. The empirical study of chronic compared with situational stereotype threat dictates the need for a measure that will assess the experience of stereotype threat over time. Our rigorous psychometric evaluation of the SVS extends Spencer's (1994) construct validation of the measure. We now have solid evidence that the SVS-4 is psychometrically robust across time and across different groups of stigmatized individuals. The SVS-4 will be crucial for future empirical research into chronic stereotype threat. It is important to note that the SVS-4 is a measure of the experience of stereotype threat, which is distinct from more dispositional measures of vulnerability to stereotype-threatening situations, such as Pinel's measure of stigma consciousness (Brown \& Pinel, 2003; Pinel, 1999) and Mendoza-Denton's measure of race-based rejection sensitivity (Mendoza-Denton, Downey, Purdie, Davis, \& Pietrzak, 2002). Measuring both dispositional and situational stereotype threat will be important in fully understanding chronic stereotype threat. Individuals' vulnerability to stereotype threat moderates in performance in stereotypethreatening situations (Brown \& Pinel, 2003). What remains unexplained are the antecedents and long-term consequences of individual differences in the vulnerability to stereotype threat.

\section{Caveats and Limitations}

Two notes of caution concern the generalizability of our findings to other stigmatized groups and the predictive power of behavioral intentions. Our findings suggest that the stereotype threat-disidentification process may not be contextually robust - that members of stigmatized groups in different environments respond to stereotype threat in different ways. Our research speaks to the experiences of high-achieving African Americans and His-panic/ Latino(a)s in the sciences, but the experiences of members of other stigmatized groups in the sciences and other domains must be addressed with further research. We specifically measured the perception of race/ethnicity-based stereotype threat in this study. Our findings indicate no moderating effect of gender, but focused studies of the gender-based experience of stereotype threat of women in the sciences should be pursued. In a similar vein, a control group of White students would be valuable to compare the decline in science identity and intention to pursue a scientific career over time and to gauge the additional burden borne by stigmatized group members above and beyond the stresses inherent in undergraduate studies.

Entering a doctoral-level scientific research career is a distal goal for our sample of undergraduate science students. To test the impact of chronic stereotype threat on the pursuit of this goal, we used intention to persist in the sciences as a proximal measure of this distal goal. Intention is not a perfect predictor, but the theory of planned behavior proposes that behavioral intentions are significant predictors of future behavior (for reviews, see Armitage \& Conner, 2001; Sheeran, 2002; Webb \& Sheeran, 2006). Empirical support of intention as a robust predictor of persistence in STEM also comes from large-scale longitudinal data sets (Eris et al., 2010; Estrada et al., 2011). Given the time course of the stereotype threatdisidentification process, we foresee that intentions and behavioral measures will both be important outcome measures in future research into chronic stereotype threat. Additionally, other types of longitudinal methods such as accelerated longitudinal designs (see Miyazaki $\&$ Raudenbush, 2000) will be useful in the pursuit of these answers. 


\section{Research on Chronic Stereotype Threat}

Despite these limitations, this research represents an important first step in the empirical study of the impact of chronic stereotype threat. During the decade and a half following the Steele and Aronson (1995) article, social psychologists have generated a rich and detailed body of research that has answered many questions about the boundary conditions of and the processes underlying situational experiences of stereotype threat. There is still a pressing need to turn our empirical attention to the adaptation to and outcomes of chronic stereotype threat. A number of converging forces suggest that the time is ripe. It is clear that the popular assumptions of the past provide inadequate explanations of many of the disparities we see and are interested in addressing. The failure of "innate lack of ability," "lack of preparation," and/or "lack of interest" to account for the disproportionate numbers of women and members of underrepresented ethnic/racial groups not pursuing academic arenas and careers underscores the importance of identifying psychological contributors. Beyond the importance of psychological explanations, there is growing recognition outside psychology that pervasive social stereotypes are contributing to these outcomes and that social psychologists have the requisite theoretical and empirical tools. Finally there is the overarching driving force of need. The underrepresentation of members of negatively stereotyped groups in academics, the sciences, and many other endeavors does not serve the long-term goals of achieving equality and diversity. Members of stigmatized groups are underrepresented in domains in which they may have significant impact. There is emerging evidence that a lack of diversity within these domains has a deleterious, but often undetectable impact on creativity and productivity (European Commission, 2003), which serve neither the goals of the specific domain nor broader society.

\section{Conclusions}

Adaptations to and long-term consequences of chronic stereotype threat have received little empirical attention. Our test of C. M. Steele's (1997) stereotype threat-disidentification hypothesis provides evidence that the contingencies tied to our social identities can indeed "make a difference in shaping our lives." After refining and validating a self-report measure of stereotype threat, we examined the impact of the experience of chronic stereotype threat over time. Analysis of longitudinal data from minority undergraduate science students across 3 academic years provides evidence for the negative impact of chronic stereotype threat on domain disidentification and persistence. We found that this process was moderated whereby domain disidentification occurred in response to chronic stereotype threat for Hispanic/Latino(a), but not for African Americans. This research offers a significant theoretical expansion of the process of the chronic experience of stereotype threat and also provides an important validation of a measure of chronic threat that will be important to further research.

\section{Acknowledgments}

Funding for this study was provided by National Institute of General Medical Sciences Grant R01-GM075316 awarded to P. Wesley Schultz. Our appreciation goes to Maria Aguilar at California State University, San Marcos, and Brian McDonald, Steve Mullet, and the Survey Research Lab at Kent State University. Portions of this article were presented at the 2011 Understanding Interventions conference in Nashville, TN, and the 2011 meeting of the Society for Personality and Social Psychology in San Antonio, TX.

\section{References}

Armitage CJ, Conner M. Efficacy of the theory of planned behaviour: A meta-analytic review. British Journal of Social Psychology. 2001; 40:471-499.10.1348/014466601164939 [PubMed: 11795063] 
Aronson J, Fried CB, Good C. Reducing the effects of stereotype threat on African American college students by shaping theories of intelligence. Journal of Experimental Social Psychology. 2002; 38:113-125.10.1006/jesp.2001.1491

Aronson J, Lustina MJ, Good C, Keough K, Steele CM, Brown J. When White men can't do math: Necessary and sufficient factors in stereotype threat. Journal of Experimental Social Psychology. 1999; 35:29-46. jesp.1998.1371.

Brown RP, Pinel EC. Stigma on my mind: Individual differences in the experience of stereotype threat. Journal of Experimental Social Psychology. 2003; 39:626- 633.10.1016/S0022-1031(03)00039-8

Burgess D, Warren J, Phelan S, Dovidio J, van Ryn M. Stereotype threat and health disparities: What medical educators and future physicians need to know. Journal of General Internal Medicine. 2010; 25:169-177.10.1007/s11606-009-1221-4 [PubMed: 19898908]

Chemers, MM. Science identity and self-efficacy. University of California; Santa Cruz: 2006. Unpublished manuscript

Cokley KO. Ethnicity, gender and academic self-concept: A preliminary examination of academic disidentification and implications for psychologists. Cultural Diversity and Ethnic Minority Psychology. 2002; 8:378-388.10.1037/1099-9809.8.4.379 [PubMed: 12416323]

Cole DA, Maxwell SE. Testing mediational models with longitudinal data: Questions and tips in the use of structural equation modeling. Journal of Abnormal Psychology. 2003; 112:558577.10.1037/0021-843X.112.4.558 [PubMed: 14674869]

Davies PG, Spencer SJ, Quinn DM, Gerhardstein R. Consuming images: How television commercials that elicit stereotype threat can restrain women academically and professionally. Personality and Social Psychology Bulletin. 2002; 28:1615-1628.10.1177/014616702237644

Davies PG, Spencer SJ, Steele CM. Clearing the air: Identity safety moderates the effects of stereotype threat on women's leadership aspirations. Journal of Personality and Social Psychology. 2005; 88:276-287.10.1037/0022-3514.88.2.276 [PubMed: 15841859]

Deaux, K.; Ethier, KA. Negotiating social identity. In: Swim, JK.; Stangor, C., editors. Prejudice: The target's perspective. San Diego, CA: Academic Press; 1998. p. 301-323.

Eris O, Chachra D, Chen HL, Sheppard S, Ludlow L, Rosca C, Toye G. Outcomes of a longitudinal administration of the Persistence in Engineering Survey. Journal of Engineering Education. 2010; 99:371-395.

Estrada M, Woodcock A, Hernandez PR, Schultz PW. Toward a model of social influence that explains minority student integration into the scientific community. Journal of Educational Psychology. 2011; 103:206-222.10.1037/a0020743 [PubMed: 21552374]

European Commission. The costs and benefits of diversity. 2003. Retrieved from http:// www.diversityatwork.net/NL/Docs/CostsBenefExSum.pdf

Hill, C.; Corbett, C.; StRose, A. Why so few? Women in science, technology, engineering, and mathematics. Washington, DC: American Association of University Women; 2010.

$\mathrm{Hu}$ L, Bentler PM. Cutoff criteria for fit indexes in covariance structure analysis: Conventional criteria versus new alternatives. Structural Equation Modeling. 1999; 6:1$55.10 .1080 / 10705519909540118$

Inzlicht M, Ben-Zeev T. A threatening intellectual environment: Why females are susceptible to experiencing problem-solving deficits in the presence of males. Psychological Science. 2000; 11:365-371.10.1111/1467-9280.00272 [PubMed: 11228906]

Keller J. Stereotype threat in classroom settings: The interactive effect of domain identification, task difficulty and stereotype threat on female students' math performance. British Journal of Educational Psychology. 2007; 77:323-338.10.1348/000709906X113662 [PubMed: 17504550]

Kiefer AK, Sekaquaptewa D. Implicit stereotypes, gender identification, and math-related outcomes: A prospective study of female college students. Psychological Science. 2007; 18:13-18.10.1111/j. 1467-9280.2007.01841.x [PubMed: 17362371]

Kline, RB. Principles and practice of structural equation modeling. 2. New York, NY: Guilford Press; 2005.

Major, B.; Schmader, T. Coping with stigma through psychological disengagement. In: Swim, J.; Stangor, C., editors. Prejudice: The target's perspective. New York, NY: Academic Press; 1998. p. 219-241. 
Massey DS, Fischer MJ. Stereotype threat and academic performance: New findings from a racially diverse sample of college freshmen. Du Bois Review: Social Sciences Research on Race. 2005; 2:45-67.10.1017/S1742058X05050058

Mendoza-Denton R, Downey G, Purdie VJ, Davis A, Pietrzak J. Sensitivity to status-based rejection: Implications for African American students' college experience. Journal of Personality and Social Psychology. 2002; 83:896-918.10.1037/0022-3514.83.4.896 [PubMed: 12374443]

Miyazaki Y, Raudenbush SW. Tests for linkage of multiple cohorts in an accelerated longitudinal design. Psychological Methods. 2000; 5:44-63.10.1037/1082-989X.5.1.44 [PubMed: 10937322]

Morgan SL, Mehta JD. Beyond the laboratory: Evaluating the survey evidence for the disidentification explanation of Black-White differences in achievement. Sociology of Education. 2004; 77:82101.10.1177/003804070407700104

Murphy MC, Steele CM, Gross JJ. Signaling threat: How situational cues affect women in math, science, and engineering settings. Psychological Science. 2007; 18:879-885.10.1111/j. 1467-9280.2007.01995.x [PubMed: 17894605]

Nussbaum AD, Steele CM. Situational disengagement and persistence in the face of adversity. Journal of Experimental Social Psychology. 2007; 43:127-134.10.1016/j.jesp.2005.12.007

Osborne JW. Race and academic disidentification. Journal of Educational Psychology. 1997; 89:728735.10.1037/0022-0663.89.4.728

Oswald DL, Harvey RD. Hostile environments, stereotype threat, and math performance among undergraduate women. Current Psychology: Developmental, Learning, Personality, Social. 2000; 19:338-356.10.1007/s12144-000-1025-5

Pinel EC. Stigma consciousness: The psychological legacy of social stereotypes. Journal of Personality and Social Psychology. 1999; 76:114-128.10.1037/0022-3514.76.1.114 [PubMed: 9972557]

Preacher KJ, Hayes AF. Asymptotic and resampling strategies for assessing and comparing indirect effects in multiple mediator models. Behavior Research Methods. 2008; 40:879-891.10.3758/ BRM.40.3.879 [PubMed: 18697684]

Rosenthal L, London B, Levy SR, Lobel M. The roles of perceived identity compatibility and social support for women in a single-sex STEM program at a co-educational university. Sex Roles. 2011; 65:725-736.

Schmader T, Major B, Gramzow RH. Coping with ethnic stereotypes in the academic domain: Perceived injustice and psychological disengagement. Journal of Social Issues. 2001; 57:93111.10.1111/0022-4537.00203

Schultz, PW. [The science study]. 2012. Unpublished raw data

Sekaquaptewa D, Thompson M. Solo status, stereotype threat, and performance expectancies: Their effects on women's performance. Journal of Experimental Social Psychology. 2003; 39:6874.10.1016/S0022-1031(02)00508-5

Shapiro JR, Neuberg SL. From stereotype threat to stereotype threats: Implications of a multi-threat framework for causes, moderators, mediators, consequences, and interventions. Personality and Social Psychology Review. 2007; 11:107-130.10.1177/1088868306294790 [PubMed: 18453458]

Sheeran P. Intention-Behavior relations: A conceptual and empirical review. European Review of Social Psychology. 2002; 12:1-36.10.1080/14792772143000003

Singham M. The canary in the mine: The achievement gap between Black and White students. The Phi Delta Kappan. 1998; 80:8-15.

Spencer, SJ. Doctoral dissertation. University of Michigan; 1994. The effect of stereotype vulnerability on women's math performance.

Spencer SJ, Steele CM, Quinn DM. Stereotype threat and women's math performance. Journal of Experimental Social Psychology. 1999; 35:4-28.10.1006/jesp.1998.1373

Steele CM. A threat in the air: How stereotypes shape intellectual identity and performance. American Psychologist. 1997; 52:613-629.10.1037/0003-066X.52.6.613 [PubMed: 9174398]

Steele CM, Aronson J. Stereotype threat and the intellectual test performance of African Americans. Journal of Personality and Social Psychology. 1995; 69:797-811.10.1037/0022-3514.69.5.797 [PubMed: 7473032] 
Steele CM, Spencer SJ, Aronson J. Contending with group image: The psychology of stereotype and social identity threat. Advances in Experimental Social Psychology. 2002; 34:379-440. 0065-2601/02.

Steele JR, James JB, Barnett RC. Learning in a man's world: Examining the perceptions of undergraduate women in male-dominated academic areas. Psychology of Women Quarterly. 2002; 26:46-50.10.1111/1471-6402.00042

Stone J. Battling doubt by avoiding practice: The effects of stereotype threat on self-handicapping in White athletes. Personality and Social Psychology Bulletin. 2002; 28:16671678.10.1177/014616702237648

Stone J, Lynch CI, Sjomeling M, Darley JM. Stereotype threat effects on Black and White athletic performance. Journal of Personality and Social Psychology. 1999; 77:12131227.10.1037/0022-3514.77.6.1213

Turner JC. Social comparison and social identity: Some prospects for intergroup behaviour. European Journal of Social Psychology. 1975; 5:1-34.10.1002/ejsp.2420050102

Webb TL, Sheeran P. Does changing behavioral intentions engender behavior change? A metaanalysis of the experimental evidence. Psychological Bulletin. 2006; 132:249268.10.1037/0033-2909.132.2.249 [PubMed: 16536643]

Woodcock, A.; Estrada-Hollenbeck, M.; Schultz, PW.; Chance, RC.; Aguilar, M.; Hernandez, PR.; Rivas, P. Tailored panel management: An integrated strategy for recruiting and retaining participants in longitudinal studies. Paper presented at the 21st meeting of the Association for Psychological Science; San Francisco, CA. 2009.

\section{Appendix. Items for the Revised Stereotype Vulnerability Scale (SVS) and the SVS-4}

Because of your ethnicity:
A. Some people believe that you have less ability.
B. If you're not better than average, people assume you
C. Professors expect you to do poorly.
D. Professors are less likely to encourage you.
E. You are not fully accepted or included into your program.
F. If you ask a simple question, people will think it is because of your ethnicity.
G. If you do poorly on a test, people will assume that it is because of your ethnicity.
H. People of your ethnicity face unfair evaluations because of their ethnicity. are limited.

Note. Items included in the shortened SVS-4 are bolded. 


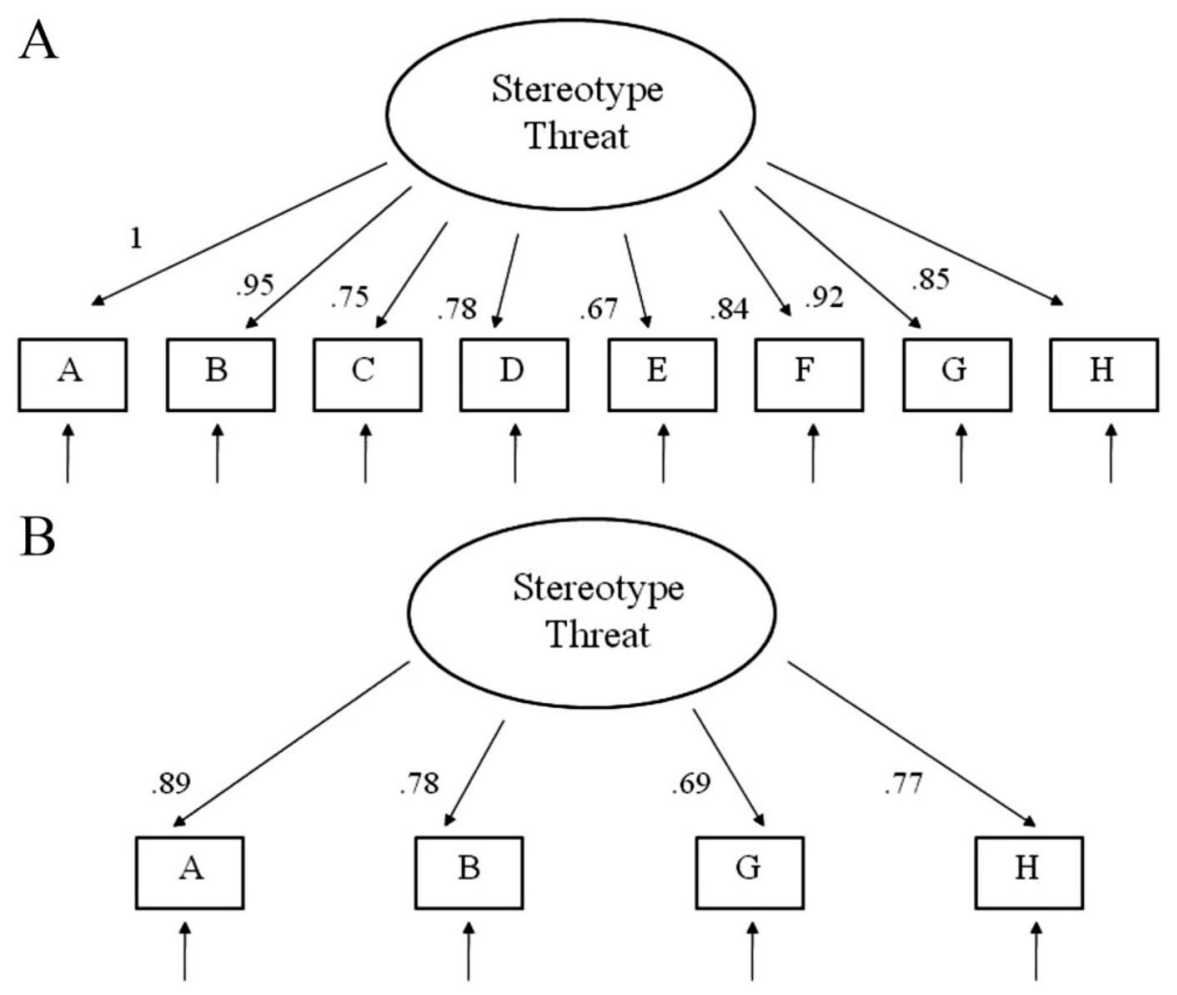

Figure 1.

Eight-item (A) and four-item (B) confirmatory factor analysis of the Stereotype Vulnerability Scale. 


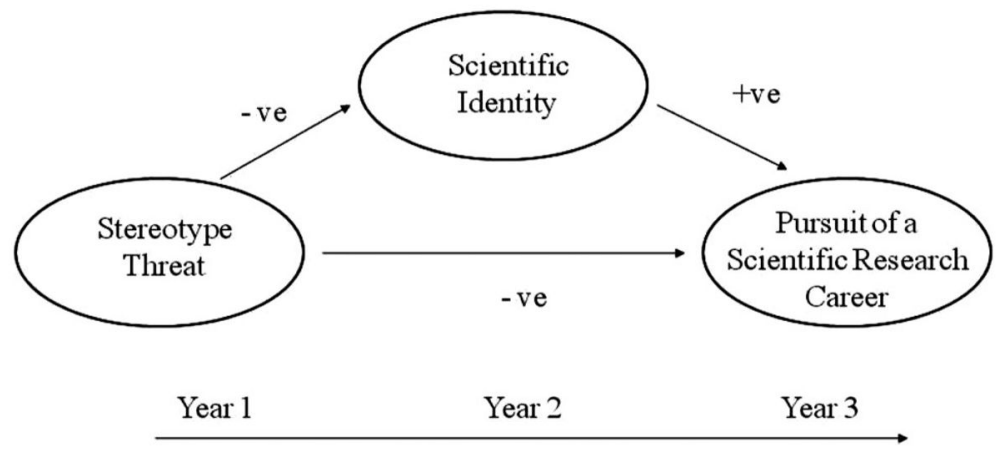

Figure 2.

Hypothesized mediation model of the relationship between stereotype threat and the pursuit of a scientific research career. -ve denotes expected negative relation, and +ve denotes expected positive relation. 


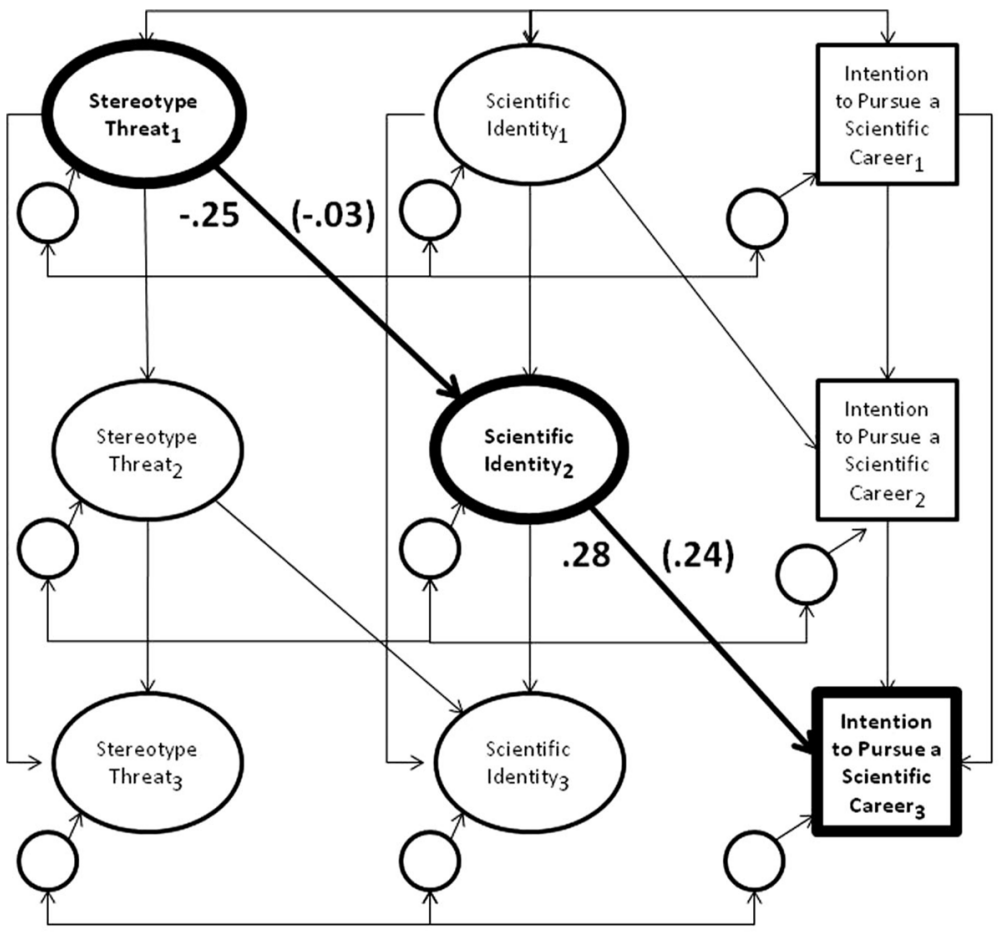

Figure 3.

Longitudinal mediation model showing the direct effects of stereotype threat on scientific disiden-tification and scientific disidentification on the pursuit of a scientific career.

Standardized coefficients for Hispanic/Latino(a) students are on the left, and the coefficients for the African American students are on the right in parentheses. 


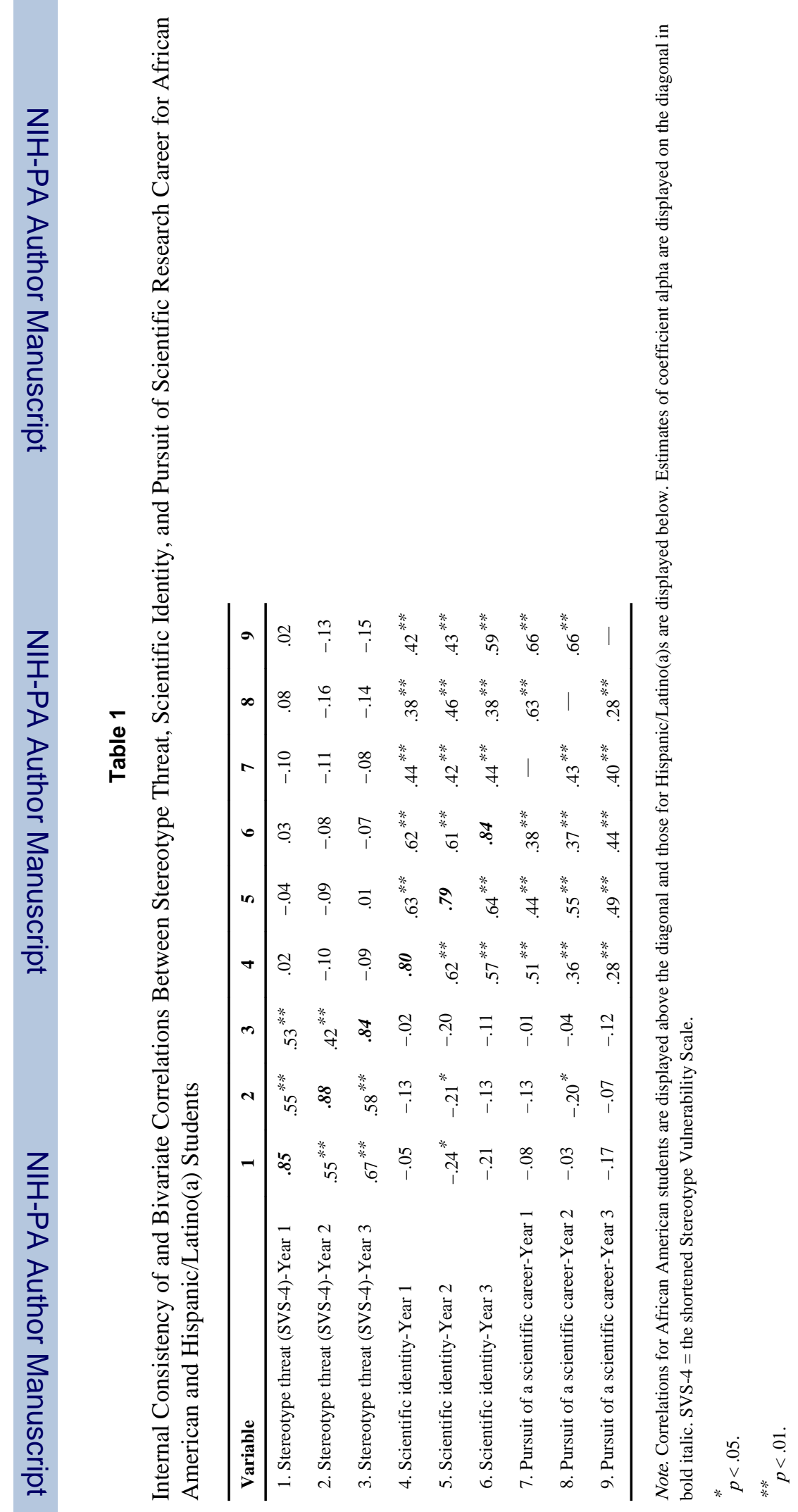




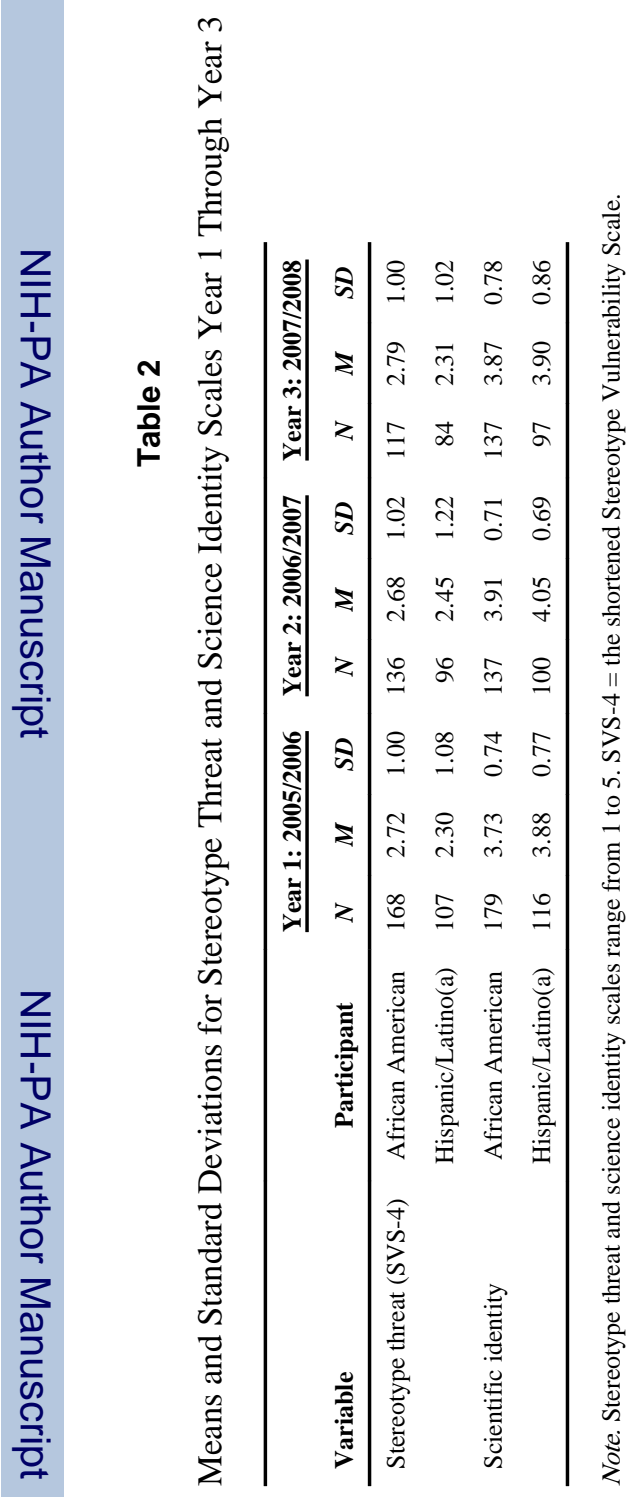

J Pers Soc Psychol. Author manuscript; available in PMC 2013 September 20. 


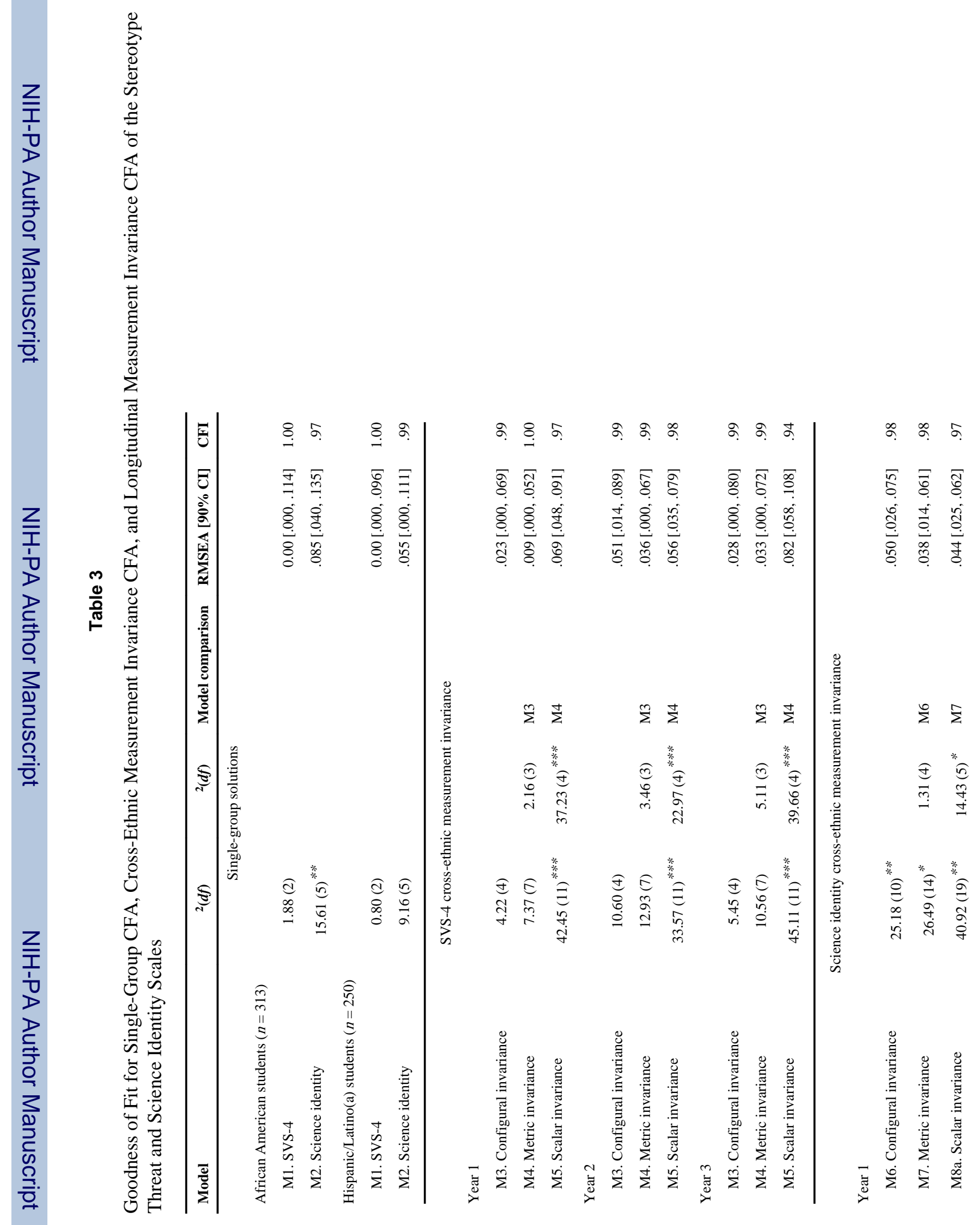




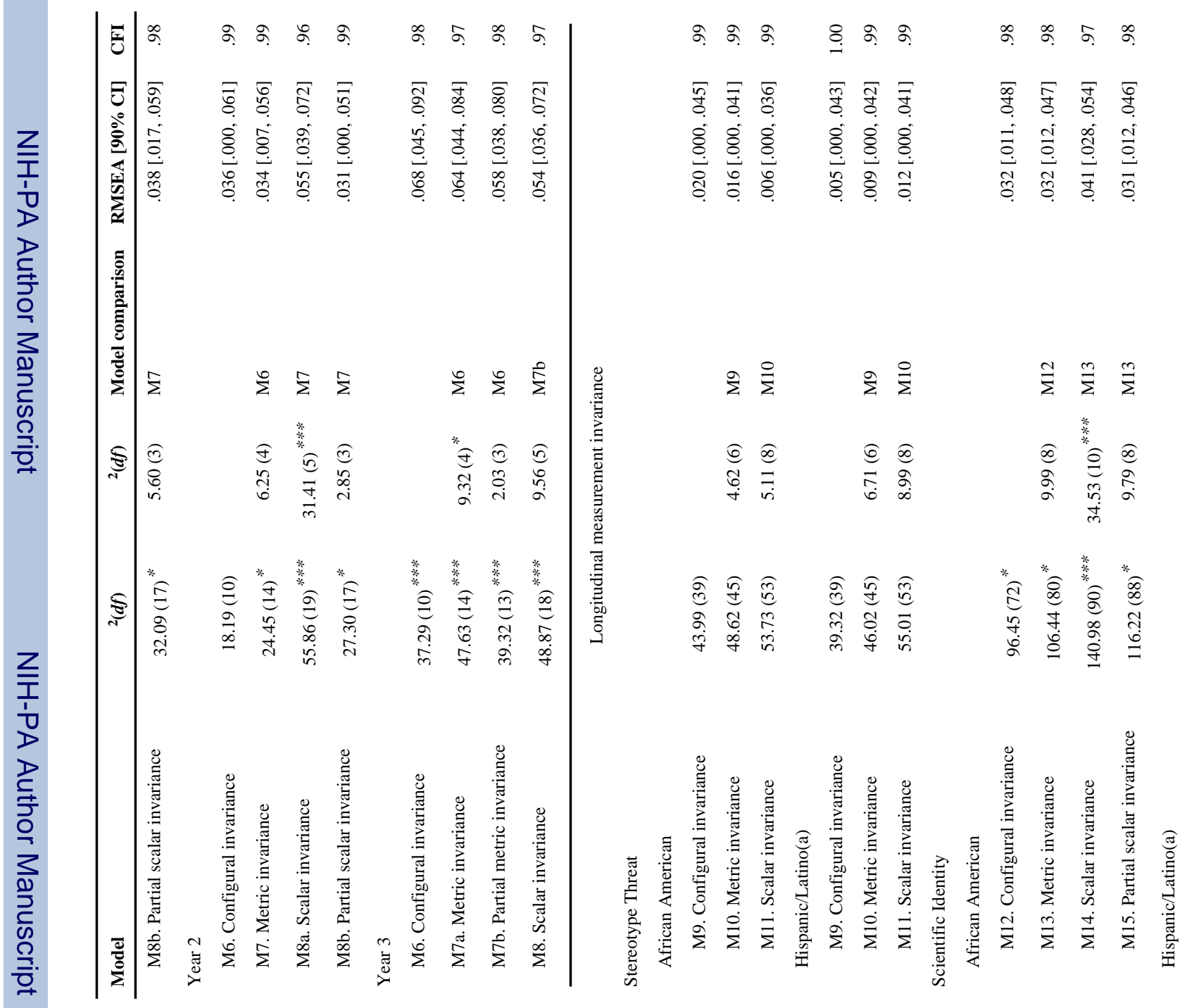




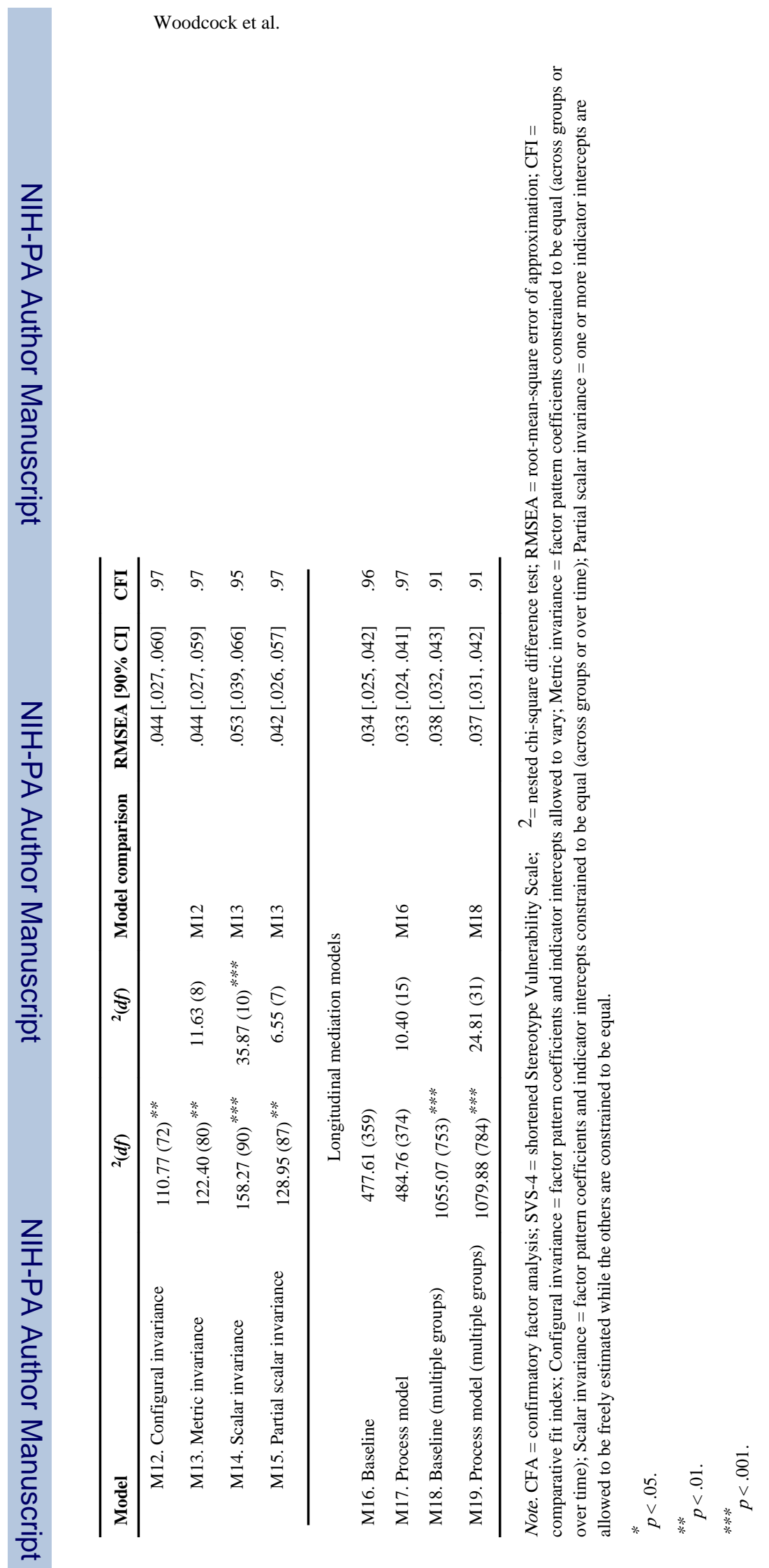

Page 24 